PAPER

\title{
The ecological imperative and its application to ethical issues in human genetic technology
}

\author{
W. Malcolm Byrnes* \\ Department of Biochemistry and Molecular Biology, Howard University College of Medicine, 520 W Street, NW, \\ Washington, DC 20059, USA
}

\begin{abstract}
As a species, we are on the cusp of being able to alter that which makes us uniquely human, our genome. Two new genetic technologies, embryo selection and germline engineering, are either in use today or may be developed in the future. Embryo selection acts to alter the human gene pool, reducing genetic diversity, while germline engineering will have the ability to alter directly the genomes of engineered individuals. Our genome has come to be what it is through an evolutionary process extending over millions of years, a process that has involved exceedingly complex and unpredictable interactions between ourselves or our ancestors and myriad other life forms within Earth's biosphere. In this paper, the ecological imperative, which states that we must not alter the human genome or the collective human genetic inheritance, will be introduced. It will be argued based on ecological principles that embryo selection and germline engineering are unethical and unwise because they will diminish our survivability as a species, will disrupt our relationship with the natural world, and will destroy the very basis of that which makes us human.
\end{abstract}

KEY WORDS: Ecological ethics $\cdot$ Bioethics $\cdot$ Ecological imperative $\cdot$ Human genetic technology

Resale or republication not permitted without written consent of the publisher

The time has come [for us] to lower our voices, to cease imposing our mechanistic patterns on the biological process of earth, to resist the impulse to control, to command, to force, to oppress, and to begin quite humbly to follow the guidance of the larger community on which all life depends.

T. Berry, 1988

\section{INTRODUCTION}

Before the events of September 11, 2001, there was heated debate in the US Congress about human cloning, with competing bills before the Senate that would ban either all cloning, or only so-called reproductive cloning but allow cloning-for-biomedicalresearch. Legislation to ban human cloning was passed recently in the US House of Representatives, and there currently is debate in the Senate on this issue. In Spring 2002, two books came out that gave us a glimpse of the power that emerging genetic and reproductive technologies could have in shaping our future as a species by bringing us into the uncharted waters of genetically engineered children. One book, written by Francis Fukuyama, warns us that such a biotechnological future will erode the very foundation of human rights (2002). The other, written by Gregory Stock, argues that a future of redesigning humanity is inevitable, and should be welcomed as the dawning of a new age in which we set a new evolutionary course for mankind (2002). As these recent events indicate, we are truly at a crossroads as a species. The questions are: How do we proceed in the midst of these challenging possibilities? And where can we find guidance?

The central argument of this paper is that one of our most reliable sources for guidance lies in the human 
genome itself because our genetic coding embodies our ecological grounding as a species. It will be argued that there is an ecological imperative not to tamper with our genetic makeup, which has resulted from millions of years of interactions among extinct and extant life forms on our living planet. The paper will be structured as follows: First, two human genetic technologies - embryo selection and germline engineering will be introduced. Second, some insights arising from a comparison between our own genome and the genomes of other organisms, which shows the profound interconnectedness of life, will be presented. Third, what will be called the ecological imperative to leave the human genome untouched will be described. Finally, this ecological imperative will be applied to the two genetic technologies that were introduced at the beginning.

\section{HUMAN GENETIC TECHNOLOGY}

In this section the discussion will be restricted to a description of a pair of human genetic technologies that belong together because both are eugenic, i.e. both allow us directly to make choices about the genetic characteristics of our children. Although one certainly could extend the list to include other technologies, only embryo selection and germline engineering will be discussed here because application of the ecological imperative is most clear-cut in their cases. Below is an introduction of the technologies and a brief presentation of some of the technical, social and ethical objections to them that have been raised.

Embryo selection often accompanies in vitro fertilization (IVF); it involves the deliberate selection of one or several embryos over others for transfer into a mother's uterus to establish pregnancy. It is used today in the fertility industry. Criteria for selection could be the absence of certain so-called genetic diseases or, increasingly, the sex of the embryo. Embryo selection involves use of a technique called preimplantation genetic diagnosis (PGD) in which a single cell from an eight-cell embryo produced by IVF is gently removed from the others and subjected to a battery of genetic tests. With the increased knowledge of the genetic basis of disease stemming from the recent sequencing of the human genome, the number of genetic tests that can be performed is predicted to increase dramatically. Thus, in the future, embryo selection most likely will become a much more sophisticated and powerful tool for controlling the genetic characteristics of our offspring.

There are many ethical and social objections to embryo selection, but the ones that will be discussed in this paper fall under the rubric of the wisdom of eugenic tampering with the human genetic inheritance. Therefore, they will be considered below in the context of the ecological imperative.

Germline engineering is qualitatively different from embryo selection because it has the potential to directly alter the genetic makeup of the engineered progeny and, in this way, change the genetic composition of the human species. In a book edited by Gregory Stock and John Campbell titled Engineering the Human Germline: An Exploration of the Science and Ethics of Altering the Genes We Pass to Our Children (2000), two different methods are presented for accomplishing germline engineering, one called gene targeting and another that involves the insertion of one or more artificial chromosomes into an embryo. The application of these methods to humans still lies in the future, but gene targeting routinely is used to produce transgenic mice, and artificial chromosomes currently are being developed by at least two biotechnology companies.

There are many ethical and social arguments against germline engineering. First, as with human cloning, the techniques involved have not yet been worked out. Like all science, perfection of techniques involves a trial and error approach. Thus, embryos will be produced and discarded as the technology develops. Many people of conscience would find such a scenario ethically objectionable. A second argument is that human life will be devalued as people are viewed as the result of manufacture, mere commodities. Ethicist Leon Kass has argued eloquently that cloning and germline engineering will result in a dehumanizing commodification of human life (1999). Finally, statements that germline engineering will be used to eliminate genetic disease ignore the fact that PGD, unethical though it may be, is already available for that purpose. Indeed, with a few rare exceptions, the most likely use of germline engineering will be for enhancement of socially valued human attributes such as intelligence and life-span. But, as the United Nations Educational, Scientific and Cultural Organization's (UNESCO's) International Bioethics Committee (IBC) points out, what is socially valued today may not be valued in the future (Galjaard 2003). Permanent alteration of a person's genome for enhancement, then, would amount to a kind of 'intergenerational tyranny', the results of which could never be reversed.

\section{THE GENOME, EVOLUTION AND THE INTERCONNECTEDNESS OF LIFE}

Now that the human genome and the genomes of dozens of other organisms have been sequenced and studied, many new insights regarding our genetic 
makeup have been gained. To review briefly, the human genome is comprised of 23 pairs of chromosomes, 22 non-sex chromosomes plus an additional pair that is either XX (female) or XY (male). The sequencing of the human genome has involved a determination of the identity and order of all the nucleotides (A, G, C, T) along the two strands of the DNA double helix in each of the chromosomes. There are billions of nucleotides in the genome, and so the sequencing effort alone represents a monumental achievement for modern biology. The next stage of the process, due to be completed soon, is to fully annotate the sequence, which involves pinpointing the locations of genes using all the information available about the structures of genes and the proteins they encode.

One insight that analysis of the human genome has given us is that a sizable fraction of our genome contains so-called 'junk' DNA, DNA for which no obvious coding function has been assigned. But recently it has been shown that these noncoding regions, which are riddled with transposons or 'jumping genes' most likely of viral origin, contain some of the very sequences that distinguish Homo sapiens from chimpanzees (Ebersberger et al. 2002, Pennisi 2002, Jordan $\&$ McDonald 2002). The insertion of transposons within noncoding regions is known to alter gene expressionin the vicinity of the insertion. Jordan \& McDonald (2002) suggest that the activity resulting from a massive burst of transpositional insertion in the human ancestor line that occurred six million years ago, around the time of the divergence between humans and chimps, may have contributed to the emergence of humans. Thus, junk DNA and the transposable elements it contains are not only functional, but also give clues about human origins.

Another insight gained is that a fraction of the genes in the human genome, surprisingly, are of bacterial origin (Andersson et al. 2001). This discovery raises the question of how these genes got into our genome. It is known that bacteria and prokaryotic microorganisms from another domain of life called Archaea easily swap genes in a process called horizontal gene transfer. While at present it seems doubtful that bacteria have actually transferred genes across biological kingdoms to humans, it is true that we humans are in fact walking communities of bacteria that dwell in our gut and other parts of our bodies. With such close contact between ourselves and these commensal bacteria within us and the long duration of that contact through evolutionary time, gene transfer does not seem like such a remote possibility after all. Reflecting the notion that our genome contains genetic pieces of various origins, Nobel laureate Joshua Lederberg suggests that we should think of ourselves as 'more than an organism.'
We are superorganisms with an extended genome that includes not only our own cells but also the fluctuating microbial genome set of bacteria and viruses that share our bodies. Some of these onetime invaders have become permanently established in our cells, even crossed the boundary line and entered our own genome.

(Lederberg 2003)

The point here is that we humans are not separate from the natural world around us, regardless of what Descartes might have said several centuries ago. The truth is that we are profoundly dependent on Earth and the biosphere for our very existence and survival. In addition to independent evolutionary processes such as chance, abiotic stress and evolutionary 'transitions', ecological contact among life forms has played a large role in shaping the identities of species, including our own, over evolutionary time. Recent discoveries in modern science, from cosmic physics to geology to atmospheric chemistry and evolutionary biology confirm this fact. Cosmic physics reveals that even the smallest deviation at the birth of the universe would have disrupted its powerful, yet delicate, 'flaring forth' and negated the future possibility of life (Berry 1988). One could say that the birth of the universe anticipated the emergence of life on earth. Geology has revealed how the physical structure of the earth is constantly being shaped and recycled by living beings, especially microorganisms, such that the bone in you or me today was once part of a coral reef eons ago. Atmospheric chemistry and evolutionary biology have suggested that the exact composition of the Earth's atmosphere is maintained by the complex ecological interplay of life, with photosynthesizing microbes and plants generating oxygen and other organisms, including animals, consuming it. Our human existence depends on this exact composition and therefore the complex interplay. The Earth, then, is one seamless whole of interconnected parts. As biologist Elisabet Sahtouris (2002) writes, it is an autopoetic unity or holon because it 'produces the very parts of which it is made and keeps them in working order by constant renewal.' A holon is 'a whole made up of its own parts, yet itself is part of a larger whole' (Sahtouris 2000), and the larger whole is the universe of holons, which is called the holarchy. Lovelock (1998) incorporates this notion of Earth as holon into what is known as the Gaia Theory, which postulates that our planet and its creatures together comprise a single self-regulating system that persists through time. Gaia is the emergent property of this system, and is analogous to a living being (Lovelock 1988).

Continuing with the theme of emergence, Francis Fukuyama, in his book Our Posthuman Future, explains how living systems have an emergent behavior that 'cannot be understood as the aggregated behavior 
of their parts' (Fukuyama 2002). In other words, the whole is greater than the sum of its parts. Scientists and mathematicians have developed algorithms to describe such nonlinear or complex adaptive biological systems (Cohen 1998). Such systems of analysis are, in a way, the opposite of reductionism because the behavior of the whole (a flock of pigeons or an ecosystem, for example) is not predictable from its component parts, but rather is an emergent property.

It is important to emphasize that, in this paper, the central tenet of Darwinian evolution - descent with modification - will be assumed as true. In its most fundamental form, Darwin's theory states that living organisms produce more offspring than can survive, so nature selects the individuals within a population that are best 'fit' for their environment. There is variation among offspring, some of which is inherited, and natural selection acts on the inherited variation. When the genetic experiments of Mendel were rediscovered by science, they were combined with Darwin's original theory, and the 'modern synthesis' of evolutionary theory was born. Neo-Darwinists who follow the tenets of the modern synthesis believe that the source of inherited variation is genetic variation that arises through the gradual accumulation of random mutations in genes. Over the long periods of evolutionary time, and with the augmentation of geographical isolation, new species will evolve. It is important to note here that, whereas the fact of evolution is accepted by nearly all practicing biologists, the driving force or mechanism of evolution, particularly as it relates to speciation, has been a matter of debate. ${ }^{1}$ Many biologists accept the central dogma that natural selection acting on random mutations is the driving force of evolution, but some biologists point to other mechanisms. A notable example is the endosymbiotic theory of speciation proposed by biologist Lynn Margulis. One aspect of the theory that is largely accepted by biologists is that cellular organelles such as the mitochondrion and the chloroplast, and even the nucleus of the eukaryotic cell, originated through symbiotic association of bacteria. However, a more controversial aspect of the theory is the prediction that the primary driving force for evolutionary innovation and speciation is 'the symbiotic acquisition of new traits by the heritance of acquired genomes.'

\footnotetext{
${ }^{1}$ Incidentally, creation scientists often will use this disagreement among biologists about the mechanism of evolution as proof that the fact of evolution is false. However, this creationist position is incorrect since study after study from many sub-disciplines of biology has shown that the theory of 'descent with modification' is as close to scientific fact as one can get
}

Margulis succinctly describes the theory as follows:

Random mutations only refine and alter, but do not produce, species-level change. Protracted symbioses lead to symbiogenesis: the origin of new organelles, organellar systems, tissues, organs, organisms, and species. Symbiogenesis, the inheritance of acquired genomes, mostly those of bacteria and other microbes, is the greatest source of evolutionary innovation. Natural selection directs evolution through propagation and elimination of what it has already. Symbiogenesis . . is the big provider of raw material that natural selection can then select.

(Margulis \& Sagan 2002, p. 157).

The arguments of Margulis \& Sagan are indeed compelling, and these authors provide numerous examples of symbiotic relationships that could represent stages of the speciation process.

Full acceptance of the endosymbiotic theory of speciation transforms the so-called 'tree of life'-with its smoothly ascending branches coming from a thick stem that originates from a single common ancestorinto a tangled web. Evolution appears to lose its directionality (if it ever had any). Indeed, Margulis and other scientists such as Stephen Jay Gould (1989) argue that evolution has no directionality, and that the increase in complexity seen through evolutionary history is not a sign of upward movement. (In fact, Gould has argued from the paleontological evidence of the Burgess Shale deposits that the tree of life should be drawn more properly as an upside-down cone rather than one that is right-side-up with a narrow base and a flared top. This is in accordance with his argument for the importance of historical contingency in evolution). And finally, removing the directionality from evolution also removes any notion of progress in evolution.

The notion of progress in evolution is objectionable because it implies that we humans can detect the direction of that progress. There appears to be no directionality to evolution, but if there is, only Earth (and God?) knows its character; we most certainly do not. And so, our response must be to humbly subordinate our often-misguided human wisdom to the wisdom of Earth. Our Western cultural heritage has carried us far from our biological roots, and we have come to see ourselves as separate from Nature. In our view, the wilderness is something to be conquered and dominated. Given how we have devastated Earth and have failed miserably to treat other beings, especially our own kind, with compassion, we would do well to listen carefully.

How can we listen, and what can we learn from Nature? Can Nature give us ethical guidance? Yes, the natural world, and our human genome with it, can serve as a valuable guide to ethical behavior. Sahtouris (2000) outlines a kind of ecological or nature ethics that would involve striving for mutual consistency, or 
shared harmony. Here, self-interest at every level of an integrated living system (a holarchy) would ensure that a shared harmony or ecological balance exists.

The [Gaian] system is worked out so that every part looks out for itself without taking more than it needs and in doing so contributes to the welfare of the whole! Every part thus finds its dynamic balance with every other part, working out mutual consistency in such a way that the whole Gaian system works a single healthy being... [emphasis hers]

(Sahtouris 2000, p 317)

It is important to emphasize that self-interest is not the same thing as selfishness, as one might find in a selfish gene, for example. Rather, self-interest, in a broad sense, can be thought of as the will to live (for an individual) or the will to continue in existence (for a species). This kind of self-interest is an intrinsic property of life itself, and is deeply rooted in us because of our natural heritage.

Of course, one difficulty we might face in trying to apply ecological ethics is that it is impossible for us limited beings to decipher what specifically constitutes the self-interest of each layer, from individuals to species to ecosystems, of living systems. The complexity is too great. Nevertheless, we can acknowledge that there is wisdom in the ecological balance of nature, and that this wisdom, forged in the fires of evolution, is embedded in the genomes of living creatures, including Homo sapiens. Regardless of whether or not we can articulate specific instructions for behavior, the wisdom is still there.

Many environmentalists argue that we must not tamper with our collective genetic inheritance-contained within the genomes of people alive today-without some proof that such tampering will not damage us as a species. This stance is in line with a general belief, known as the precautionary principle, that has been applied to policies regarding the use of agricultural biotechnology and genetically modified crops in Europe. Basically, the principle states that the burden of proof that a particular technology is not harmful (to the environment, a species, or an individual) rests on the proponents of the technology, not the opponents. In the case of human germline engineering, proof of safety would in all likelihood not be possible due to the complexity of the human body and uncertainty about effects of even single-gene changes. UNESCO's IBC reflects this thinking in its recommendation that germline engineering not be allowed:

...[A]ny genetic change of germ cells or early embryos may be passed to future generations which may imply irreversible risks. Given these facts, the complexity of the relationships between genes and environment, and the notion that some genes that are associated with disease may be beneficial in another context, the most elemen- tary prudence requires that germline intervention should not be undertaken on the basis of the 'precautionary principle.'

(Galjaard 2003, p 11)

\section{THE ECOLOGICAL IMPERATIVE AND ITS APPLICATION TO ETHICAL ISSUES}

What is the ecological imperative, and how can it be applied to ethical issues in human genetic technology? Following and extending the spirit of the precautionary principle, what will be called the ecological imperative states that we must not tamper with the genomes of organisms in such a manner as to disrupt the functioning of Earth. All life on Earth is interconnected, and all living things interact within the planet's global ecosystem. The Earth has evolved into its present mode of being through 4.6 billion years of development, with life present for about three-quarters of that time. Healthy ecosystems are integral to the functioning of Earth. Environmental groups apply this thinking when they argue against the creation of genetically modified plants and animals - both because genetic modification destroys the integrity of the organism and because release of such organisms into the natural environment can wreak havoc on ecosystems.

The ecological imperative can be applied to humans. Simply put, it says that we must not alter the collective genetic inheritance of the human species. There are several ways that people can directly control the genes they pass on to their children, i.e. practice eugenics. The human genetic technologies mentioned aboveembryo selection and germline engineering - are two of them. (Sterilization and reproductive isolation, two rather primitive ways of carrying out eugenics, were used at the height of the eugenics movement, a time when the modern technology we have today was not available.)

The ecological imperative strongly argues against germline engineering for two major reasons. First, the human genome, like the genome of any other living creature, was formed out of a rich and wondrous evolutionary history. The human genome is exactly as it is through no accident; one might say that it is sacred, and thus is deserving of profound respect. The human genome is sacred because it reflects the sacred community of the natural world. While we humans are not at the apex of evolutionary development, we do have reflective consciousness, a mysterious emergent property that may have arisen in Homo sapiens around the time we acquired language. And, although consciousness may be present to some degree in all living things - indeed may be an intrinsic property of life itself - no other creature except us has the reflective ability to see themselves in the context of the world around them. This ability makes us special; it also is 
very powerful. Through our culture and our powerful technology, we have altered the basic life systems of Earth. (The effects of global warming are an example.) We have that ability. For this reason, it is imperative that we not alter our genome. We do not know how our unique human abilities, such as consciousness, are connected to our biology. But we do know that it took the history of the entire universe up to that point for consciousness to arise. We are indeed part of the cosmic order, and although we cannot say that we are at its summit, we do have a role to play in the history of life.

The second major reason we should not alter our genome is related to our biological complexity. We simply do not know how changing even a single gene within our genome will affect the expression of other genes. We do not know how genes interact with each other inside the cells of our bodies. These systems are unbelievably complex. And while scientists in the field of systems biology are using the modern technologies of genomics, proteomics and bioinformatics to understand the nature of these interactions for important medical goals, we nevertheless will be unable to define all of the interactions. For this reason, there will always be unintended consequences of genomic modification. The system is just too complex. Moreover, life processes emerge out of the whole system and cannot be predicted by analyzing the parts, no matter how well the details of the interactions among the parts are understood. Ironically, genetic modifications designed to eliminate genetic disease or enhance natural abilities may actually weaken the constitution of individuals and of the species because they go against ecological principles. In other words, the health of engineered individuals, as well as the health and survivability of the human species, may be threatened by germline engineering.

The ecological imperative argues against embryo selection (or PGD) as well because, like germline engineering, it seeks to modify the genetic composition of future generations. PGD is used in the IVF clinic to select only the one or two embryos with the right genetic profile out a batch of ten or so for transfer into a mother's uterus. One might think that an ecological imperative would lead one to precisely the opposite position, i.e. that embryo selection would be advantageous for the human population since it would help to weed out undesirable disease genes. But this is not true for the following reason.

It is impossible to gaze into the evolutionary future and see which genes will be good and which will be bad for humanity. (There actually is no such thing as a good or a bad gene.) We have learned that the genetic mutation that leads to sickle cell anemia in homozygous form is clearly advantageous to persons who are carriers of the sickle cell trait, i.e. are heterozygotes. Being heterozygous brings with it a partial immunity to malaria. Apparently, the presence of the modified form of the hemoglobin found in such persons, which is responsible for the sickling of red blood cells and other effects, interferes with the life cycle of the malarial parasite. The so-called defective sickle cell gene has persisted in human populations in sub-Saharan Africa and certain regions of the Mediterranean where malaria is common. It confers an evolutionary advantage.

What is said about the sickle cell trait can be said about any genetic defect or disease gene. We do not know how the gene might interact with other genes in the cell and in the body. From a larger ecological perspective, we do not know how the presence of a particular gene in the human population impacts our interaction with our environment. If disease genes have persisted in populations, there must be a good ecological reason for it. Perhaps the ancillary effects of the gene outweigh the disease effects in certain environmental contexts. Changing our genetic makeup may diminish our survivability as a species. So-called disease genes have evolved in us over the course of time. Do we really know whether or not they are 'mistakes' to be corrected or eliminated? Thus, embryo selection and other eugenic technologies such as germline engineering are unwise for ecological reasons. Of course, this argument does not imply that we should not seek medical treatments for persons who do have inherited diseases. In fact, this is where our medical resources should be used, rather than for eliminating such persons in the first place.

\section{CONCLUSIONS}

In conclusion, the ecological imperative tells us that we must not tamper with the human genome because within it is the key to our survival as a biological species. We must not tamper with our collective genetic inheritance through use of the eugenic technologies of embryo selection and germline engineering. We have no clear idea why Nature, in her wisdom, selects the genes she does to include in our genome - even genes from bacteria and viruses. But, we do know that we are who we are because we have the genome we have. Our genome has been formed through the wondrous process of evolution, which has involved myriad complex interactions among the inhabitants of Earth's biosphere over millions of years. And, we are still evolving.

As a species, we Homo sapiens are at a crossroads. Technologies are on the horizon or are already here that will allow us to change the essence of our humanity. All of our uniquely human attributes, be they our 
reflective consciousness or our ability to love others, are ultimately linked to our biological inheritance. And, while one may argue that the effect of embryo selection or germline engineering on the human gene pool will be miniscule because the number of people whose genomes will be modified will be small compared to the enormous size of the human population, we still need to ask: Do we want to go down that road? No. The risks are too great, and the future of our species is at stake.

But, there is another reason. We have an obligation to Earth, who has nourished us into being through these many millions of years. We are just now beginning to break free of our anthropocentric view of ourselves as being separate from or above Earth and her creatures. If we begin modifying our own nature, 'stepping outside the Tao' as C. S. Lewis would say (1974), how will we be able to usher Earth through this terrible predicament in which we have placed her? No, if we do this, we surely will have lost our way. We may not be able to step back from the precipice.

\section{LITERATURE CITED}

Andersson J, Doolittle WF, Nesbo C (2001) Are there bugs in our genome? Science 292: 1848-1850

Berry T (1988) The dream of the earth. Sierra Club Books, San Francisco, CA

Cohen JE (1998) Cooperation and self-interest: pareto-inefficiency of Nash equilibria in finite random games. Proc

Editorial responsibility: Mary Batson (Managing Editor), Oldendorf/Luhe, Germany
Natl Acad Sci USA 95: 9724-9731

Ebersberger I, Metzler D, Schwarz C, Paabo S (2002) Genomewide comparison of DNA sequences between humans and chimpanzees. Am J Hum Genet 70:1490-1497

Fukuyama F (2002) Our posthuman future: consequences of the biotechnology revolution. Farrar, Straus and Giroux, New York, NY

Galjaard H (2003) Report of the IBC on pre-implantation genetic diagnosis and germ-line intervention. UNESCO Document Code SHS.2003/WS/26; SHS/EST/02/CIB-9/2 REV.3. UNESCO, Paris

Gould SJ (1989) Wonderful life: the Burgess Shale and the nature of history. W. W. Norton and Co, New York, NY

Jordan IK, McDonald JF (2002) A biologically active family of human endogenous retroviruses evolved from an ancient inactive lineage. Genome Lett 1:105-109

Kass L (1999) The moral meaning of genetic technology. Commentary Magazine 108: 32-38

Lederberg J (2003) Getting tune with the enemy-microbes. The Scientist 17:20-21

Lewis CS (1974) The abolition of man. HarperCollins, New York, NY

Lovelock JE (1988) The ages of Gaia: a biography of our living earth. Norton, New York, NY

Margulis L, Sagan D (2002) Acquiring genomes: a theory of the origin of species. Basic Books, New York, NY

Pennisi E (2002) Jumbled DNA separates chimps and humans. Science 298: 719-720

Sahtouris E (2000) Earthdance: living systems in evolution. iUniversity Press, New York, NY

Stock G (2002) Redesigning humans: our inevitable genetic future. Houghton Mifflin Co, Boston, MA

Stock G, Campbell J (eds) (2000) Engineering the human germline: an exploration of the science and ethics of altering the genes we pass to our children. Oxford University Press, New York, NY

Submitted: May 28, 2003; Accepted: July 25, 2003

Proofs received from author(s): August 20, 2003

Published on the web: August 21, 2003 